\title{
Insights Into the Roles of Two Genes of the Histidine Biosynthesis Operon in Pathogenicity of Xanthomonas oryzae pv. oryzicola
}

\author{
Panpan Su, Zhiwei Song, Guichun Wu, Yancun Zhao, Yuqiang Zhang, Bo Wang, \\ Guoliang Qian, Zheng Qing Fu, and Fengquan Liu ${ }^{\dagger}$
}

First, second, fourth, and ninth authors: Institute of Plant Protection, Jiangsu Academy of Agricultural Science, Nanjing 210014, China; third, fifth, sixth, seventh, and ninth authors: College of Plant Protection, Nanjing Agricultural University, Nanjing 210095, China/Key Laboratory of Integrated Management of Crop Diseases and Pests (Nanjing Agricultural University), Ministry of Education, China; and eighth author: Department of Biological Sciences, University of South Carolina, Columbia.

Accepted for publication 15 December 2017.

\begin{abstract}
Xanthomonas oryzae pv. oryzicola is an $X$. oryzae pathovar that causes bacterial leaf streak in rice. In this study, we performed functional characterization of a nine-gene his operon in X. oryzae pv. oryzicola. Sequence analysis indicates that this operon is highly conserved in Xanthomonas spp. Auxotrophic assays confirmed that the his operon was involved in histidine biosynthesis. We found that two genes within this operon, $\operatorname{trpR}$ and his $B$, were required for virulence and bacterial growth in planta. Further research revealed that $\operatorname{trpR}$ and hisB play different roles in $X$. oryzae pv. oryzicola. The trpR acts as a transcriptional repressor and could

negatively regulate the expression of his $G,-D,-C,-B,-H,-A$, and $-F$. his $B$, which encodes a bifunctional enzyme implicated in histidine biosynthesis, was shown to be required for xanthomonadin production in $X$. oryzae pv. oryzicola. The disruption of hisB reduced the transcriptional expression of five known shikimate pathway-related genes $x a n B 2$, aroE, aroA, aroC, and aroK. We found that the his operon in X. oryzae pv. oryzicola is not involved in hypersensitive response in nonhost tobacco plants. Collectively, our results revealed that two genes in histidine biosynthesis operon play an important role in the pathogenicity of $X$. oryzae pv. oryzicola Rs 105 .
\end{abstract}

Xanthomonas oryzae pv. oryzicola is a Gram-negative bacterium and the causal agent of bacterial leaf streak (BLS) of rice. X. oryzae pv. oryzicola causes significant economic losses in many rice growing countries in Asia annually, especially in China (Niño-Liu et al. 2006; Zhao et al. 2011). During infection, X. oryzae pv. oryzicola enters host plants mainly through stomata or wounds of the leaves and multiplies in the substomatal cavity. The colonization of $X$. oryzae pv. oryzicola in the intercellular spaces of the mesophyll, causes water-soaked interveinal lesions on rice leaves (Wang et al. 2007). This pathogen is characterized by typical yellow pigments known as xanthomonadins.

L-Histidine is one of the 20 natural amino acids found in proteins of living organisms. The side- chain of this amino acid consists of an imidazole ring and produces a $\mathrm{pKa}$ of 6.0; as such, histidine residues can act as an acid or a base in enzymatic reactions (Kulis-Horn et al. 2014; Polgár 2005; Rebek 1990).

L-histidine biosynthesis is a comprehensively elucidated ancient metabolic pathway present in different organisms. For decades, L-histidine biosynthesis has been investigated mainly in Escherichia coli and its close relative Salmonella typhimurium. Fundamental biological mechanisms, including operon structure, have been discovered. Moreover, histidine biosynthesis seems to be conserved in most organisms including bacteria, archaea, lower eukaryotes, and plants (Chapman and Nester, 1969; Fink 1964; Kulis-Horn et al.

†Corresponding Author: F. Liu; E-mail: fqliu20011@sina.com

First and second authors contributed equally to this work.

This work was supported by the National Natural Science Foundation of China (31371906; 31571974), Postdoctoral Foundation of Jiangsu Province (1601077C), and Special Fund for Agro-Scientific Research in the Public Interest (201303015).

*The $\boldsymbol{e}$-Xtra logo stands for "electronic extra" and indicates that two supplementary figures and three supplementary tables are published online.

(c) 2018 The American Phytopathological Society
2014; Lee et al. 2008; Stepansky and Leustek, 2006). Histidine biosynthesis pathway requires a series of 10 enzymatic reactions which transform the substrate ATP and phosphoribosyl pyrophosphate (PRPP) to become L-histidine (Alifano et al. 1996; Fani et al. 1995). In E. coli and $S$. typhimurium, the 10 enzymatic activities are encoded by eight genes, namely his $A,-B,-C,-D,-F,-G,-H$, and $-I E$, which are organized in a single operon (Alifano et al. 1996; Carlomagno et al. 1988; Chiariotti et al. 1986; Fani et al. 1997; Fink 1964; Jung et al. 1998). Although hisI and hisE were considered two separate genes, further studies have confirmed that hisI and hisE are a single gene (Chiariotti et al. 1986).

Histidine biosynthesis plays an important role in cellular metabolism. Histidine biosynthesis and purine biosynthetic pathways are linked by 1-(5'-phosphoribosyl)-5-amino-4-imidazolecarboxamide (AICAR), a by-product of histidine synthesis and intermediate of purine biosynthesis (Bochner and Ames 1982; Klem and Davisson 1993; Papaleo et al. 2009). On the other hand, histidine biosynthesis is regulated not only by histidine, but also by other molecules. For example, the activity of the first enzyme of histidine biosynthesis is inhibited by histidine but is stimulated by PRPP and ATP (Alifano et al. 1996; Wiater et al. 1971). Under moderate amino acid starvation and in cells growing in a minimal medium, his operon expression is positively regulated by the alarmone guanosine $5^{\prime}$-diphosphate $3^{\prime}$ diphosphate (ppGpp), which is the effector of stringent responses (Alifano et al. 1996; Jung et al. 2010; Kulis-Horn et al. 2014).

Histidine biosynthesis in $X$. oryzae pv. oryzicola and other Xanthomonas spp. has been rarely explored. In $X$. oryzae pv. oryzicola, the histidine biosynthetic pathway also requires 10 enzymatic reactions, which are encoded by eight genes (his $A,-B$, $-C,-D,-F,-G,-H$, and $-I E$ ), through BLAST search and KEGG pathway analysis (http://www.kegg.jp/kegg-bin/show_pathway? 148397042654630/xor00340.args). Meanwhile, bioinformatics analysis shows that gene trpR (XOC_2214), which is upstream of his $G$, encodes a transcriptional regulator. In this research, we identified two histidine biosynthesis related genes $\operatorname{trp} R$ and $h i s B$, as important virulence determinants in $X$. oryzae pv. oryzicola. Our 
data revealed that $\operatorname{trp} R$ could negatively regulate the expression of his $A,-B,-C,-D,-F,-G$, and $-H$. Furthermore, we also found that his $B$ affected the production of xanthomonadins in $X$. oryzae pv. oryzicola. To the best of our knowledge, this is the first study to perform a functional analysis of trpR and hisB in Xanthomonas.

\section{MATERIALS AND METHODS}

Bacterial strains, plasmids, and culture conditions. The information regarding the bacterial strains and plasmids related to this work is presented in Supplementary Table S1. All the E. coli

A

Xanthomonas oryzae pv. oryzicola

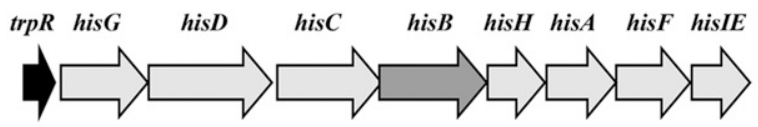

Xanthomonas oryzae pv. oryzae

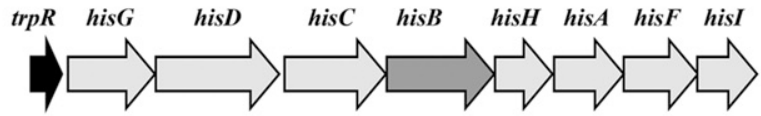

Xanthomonas axonopodis pv. citri

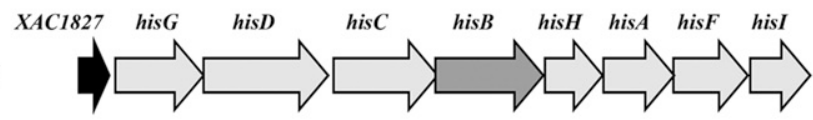

Xanthomonas campestris pv. citri
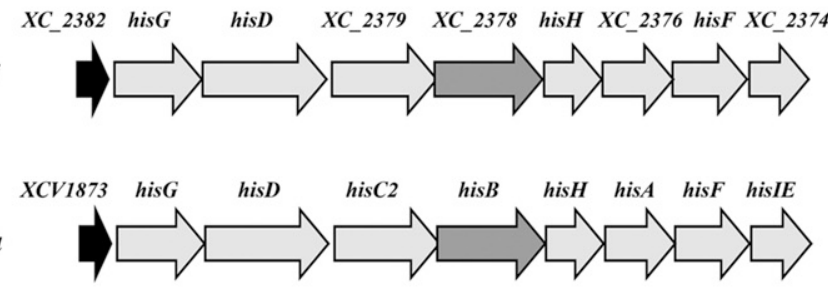

$\underline{1 k b}$

B

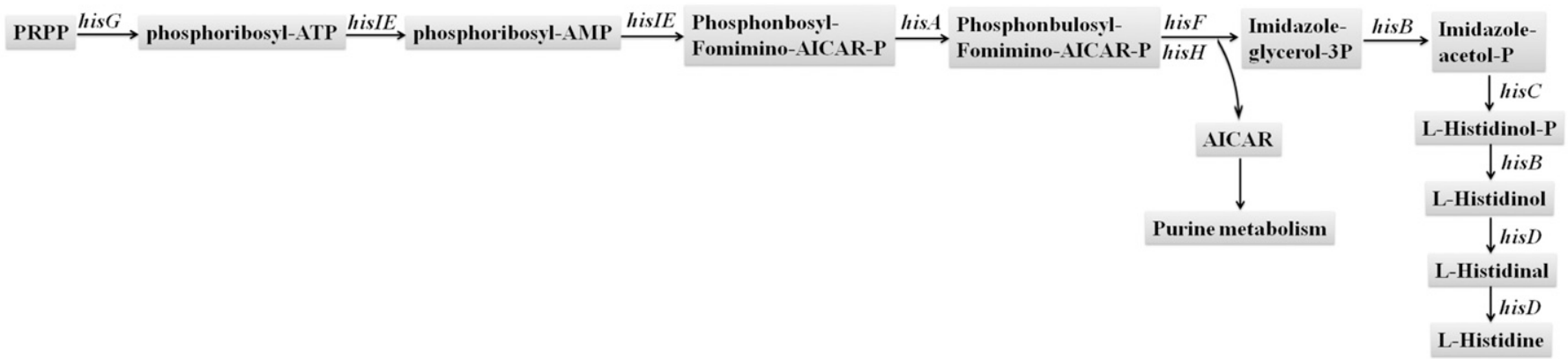

Fig. 1. Genetic structure of the his operon and metabolic pathway of histidine biosynthesis in X. oryzae pv. oryzicola and other related Xanthomonas. A, The direction of the arrow and the length of the box represent transcription direction and gene size. The data in this figure are based on GenBank database of $X$. oryzae pv. oryzicola BLS256, X. oryzae pv. oryzae PXO99A, X. axonopodis pv. citri 306, X. campestris pv. campestris 8004, and X. campestris pv. vesicatoria 85-10. XAC1827, XC_2382, and XCV1873 were the homologs of trpR. B, The metabolic pathway of histidine biosynthesis of X. oryzae pv. oryzicola (http://www.kegg.jp/). PRPP, phosphoribosyl pyrophosphate; AICAR, 1-(5-phosphoribosyl)-5-amino-4-imidazolecarboxamide.

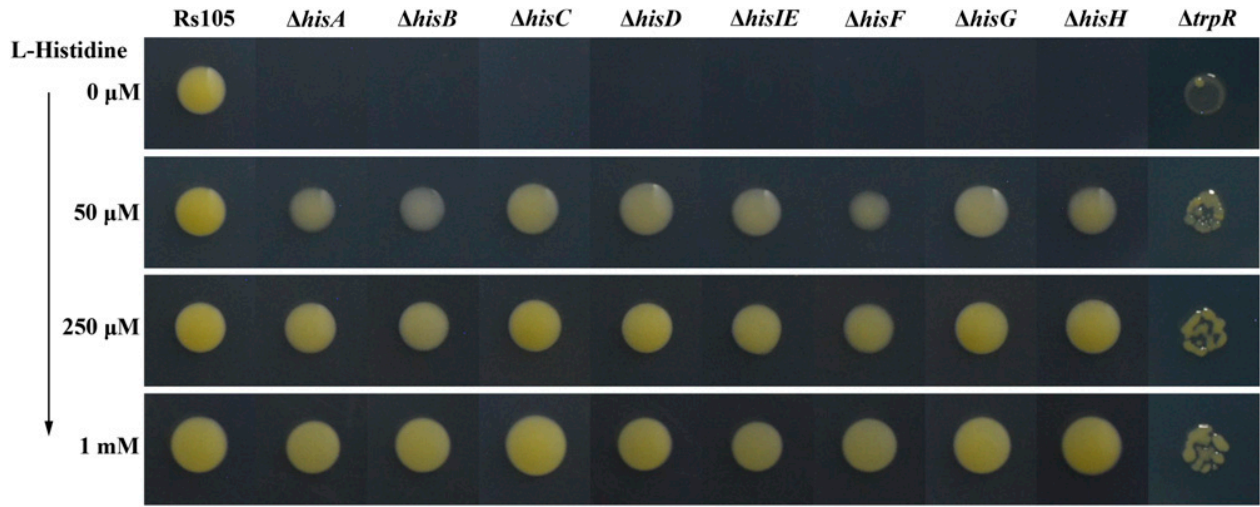

Fig. 2. Growth of Xanthomonas oryzae pv. oryzicola strains in XOM3 minimal medium supplemented with different concentrations of L-histidine. Bacterial cultures were spotted and cultured for 5 days at $28^{\circ} \mathrm{C}$ on XOM3 agar plates, which were supplemented with L-histidine with respective concentrations of $0 \mu \mathrm{M}$, $50 \mu \mathrm{M}, 250 \mu \mathrm{M}$, and $1 \mathrm{mM}$. Rs105, the wild-type strain of $X$. oryzae pv. oryzicola; $\Delta$ hisA, the hisA deletion mutant; $\Delta$ hisB, the hisB deletion mutant; $\Delta$ hisC, the his $C$ deletion mutant; $\triangle$ hisD, the hisD deletion mutant; $\triangle$ hisIE, the hisIE deletion mutant; $\Delta$ hisF, the hisF deletion mutant; $\Delta$ his $G$, the his $G$ deletion mutant; $\Delta h i s H$, the his $H$ deletion mutant; and $\Delta \operatorname{trpR}$, the $\operatorname{trp} R$ deletion mutant. Three replicates for each treatment were used, and the experiment was repeated three times. Data were from a representative experiment, and similar results were reported from two other independent experiments. 
strains were cultivated at $37^{\circ} \mathrm{C}$ in Luria-Bertani (LB) broth or LB agar plates. Wild-type strain Rs 105 of $X$. oryzae pv. oryzicola and its derivative strains were grown at $28^{\circ} \mathrm{C}$ in nutrient broth (NB) medium (beef extract, $3 \mathrm{~g} /$ liter; yeast extract, $1 \mathrm{~g} / \mathrm{liter}$; polypeptone, $5 \mathrm{~g} /$ liter; and sucrose, $10 \mathrm{~g} /$ liter) or on nutrient agar (NA) unless specified. XOM3 (1.8 g/liter D-xylose, $670 \mu \mathrm{M} \mathrm{D}$, Lmethionine, $10 \mu \mathrm{M}$ sodium L-glutamate, $240 \mu \mathrm{M} \mathrm{NaFe}{ }^{2+}$-EDTA, $5 \mu \mathrm{M} \mathrm{MgCl}_{2}, 14.7 \mathrm{mM} \mathrm{KH_{2 } \mathrm { PO } _ { 4 } , 4 0 \mu \mathrm { M } \mathrm { MnSO }}$, pH 6.0) was used as minimal medium. Antibiotics were added to the medium as required, with the following final concentrations: ampicillin (Amp), $100 \mu \mathrm{g} / \mathrm{ml}$; kanamycin (Kan), $50 \mu \mathrm{g} / \mathrm{ml}$; and rifampicin (Rif), $100 \mu \mathrm{g} / \mathrm{ml}$.

Generation of gene deletion mutants and complemented strains. The in-frame deletion mutants of target genes were generated from the $X$. oryzae pv. oryzicola wild-type Rs 105 by allelic homologous recombination, and the suicide vector $\mathrm{pK} 18 \mathrm{mobsacB}$ was used in the process (Qian et al. 2013a; Zhao et al. 2011; Zou et al.
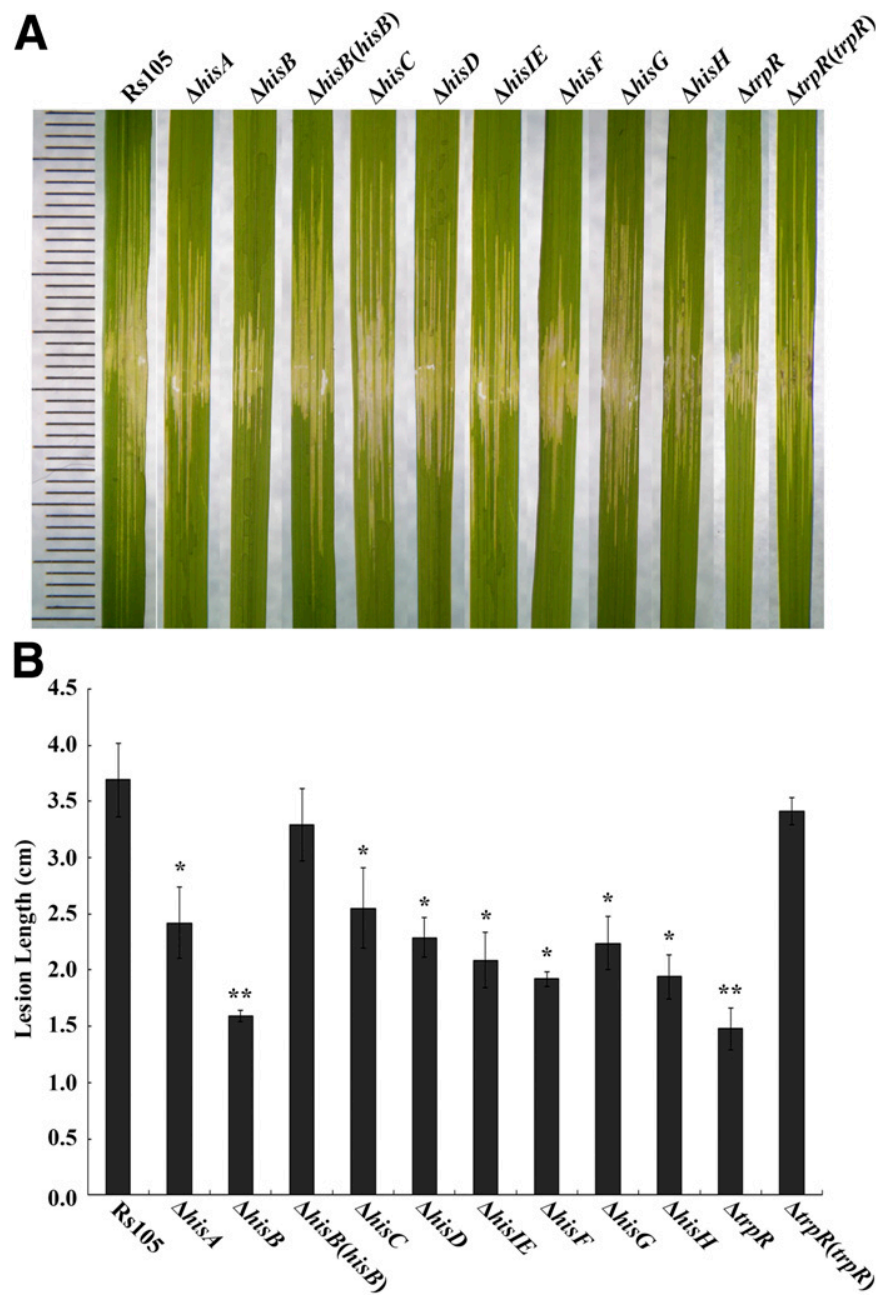

Fig. 3. Pathogenicity test of Xanthomonas oryzae pv. oryzicola strains in rice. A, Lesion lengths on the leaves of rice seedlings (cultivar Shanyou63, 2 weeks old) by infiltration with $X$. oryzae pv. oryzicola strains. B, Calculated data of lesion length on the leaves of rice seedlings (Shanyou63, 2 weeks old) inoculated with $X$. oryzae pv. oryzicola strains. Rs 105, the wild-type strain of $X$. oryzae pv. oryzicola; $\triangle$ hisA, the hisA deletion mutant; $\Delta$ his $B$, the hisB deletion mutant; $\Delta$ hisB (hisB), the complemented strain of $\Delta$ his $B ; \Delta$ hisC, the hisC deletion mutant; $\triangle$ hisD, the hisD deletion mutant; $\triangle$ hisIE, the hisIE deletion mutant; $\triangle h i s F$, the hisF deletion mutant; $\triangle$ his $G$, the hisG deletion mutant; $\Delta h i s H$, the his $H$ deletion mutant; $\triangle \operatorname{trpR}$, the $\operatorname{trpR}$ deletion mutant; and $\Delta \operatorname{trpR}$ $(\operatorname{trpR})$, the complemented strain of $\Delta t r p R$. The experiment was repeated three times. Data were the means \pm standard deviations from three repeats, each with 10 leaves. Vertical bars represent standard errors. * indicates differences between mutant and wild-type strain Rs105 at $P=0.05$; ** indicates a significant difference between mutant and the wild-type Rs105 at $P=0.01$.
2011). Two flanking regions of each gene were generated through PCR amplification by using different primer pairs. PCR fragments of each gene were digested with appropriate restriction enzymes and ligated into the vector $\mathrm{pK} 18 \mathrm{mobsacB}$, creating individual recombinant vectors. These recombinant vectors were transformed into wildtype Rs105 by electroporation, and NA plates lacking sucrose and supplemented Rif $(100 \mu \mathrm{g} / \mathrm{ml})$ and $\mathrm{Km}(50 \mu \mathrm{g} / \mathrm{ml})$ were used to select transformants. Positive colonies were plated on NA plates containing $10 \%$ (wt/vol) sucrose and Rif $(100 \mu \mathrm{g} / \mathrm{ml})$ to select the second crossover events and these in-frame deletion mutants were confirmed through PCR (Supplementary Table S2). For complementation, each intact gene and the predicted promoter were amplified through PCR method using their corresponding primers, and were cloned into the complemented vector pUFR034 (De Feyter et al. 1990). The resultant constructs were transferred into the corresponding mutants by electroporation to generate these complemented strains and were confirmed through PCR, as previously described (Qian et al. 2013a; Zhao et al. 2011).

Auxotrophic assays. The auxotrophic assays of each strain were performed as described previously with some modification (Park et al. 2007). In brief, X. oryzae pv. oryzicola strains were cultured in NB medium until midlogarithmic phase (optical density at $\left.600 \mathrm{~nm}\left[\mathrm{OD}_{600 \mathrm{~nm}}\right]=1.0\right)$. Cells were collected by centrifugation at 6,000 rpm and were washed twice with sterile $\mathrm{ddH}_{2} \mathrm{O}$. Each culture was resuspended with an equal volume of sterile $\mathrm{ddH}_{2} \mathrm{O}$. Then, $3 \mu$ of bacterial cultures was spotted on XOM3 agar plates supplemented with L-histidine (Sigma) with respective concentrations of $0 \mu \mathrm{M}, 50 \mu \mathrm{M}, 250 \mu \mathrm{M}$, and $1 \mathrm{mM}$. The preparations were cultured for 5 days at $28^{\circ} \mathrm{C}$. Experiments were repeated at least three times.

Pathogenicity assay and measurement of bacterial growth in planta. Pathogenicity assays were performed in a greenhouse at 22 to $30^{\circ} \mathrm{C}$ with a $70 \%$ relative humidity (Qian et al. 2013b; Zhao et al. 2011). In brief, wild-type (Rs105) and mutant strains were cultivated in NB medium at $28^{\circ} \mathrm{C}$ and $200 \mathrm{rpm}$. All strains were adjusted to a density of $\mathrm{OD}_{600 \mathrm{~nm}}=0.5$ with $\mathrm{ddH}_{2} \mathrm{O}$. Bacterial suspension was infiltrated by using a needleless syringe and was inoculated into the 2-week-old rice leaves of cultivar Shanyou63 (susceptible to the pathogen). Each bacterium was inoculated into 10 leaves. The lesions length was measured after 10 days postinoculation, and representative leaves were collected for photos. The experiment was performed three times.

Measurement of bacterial growth in rice leaf tissue was carried out as described previously (Qian et al. 2013a; Zhao et al. 2012). Briefly, the study of the colonization of each X. oryzae pv. oryzicola strain was performed by homogenizing five inoculated leaves in $9 \mathrm{ml}$ of sterile water. The leaves were cut in $6 \mathrm{~mm}$ sections around the inoculation spots after 1, 5, and 10 days after inoculation. After dilution of the homogenates, the resulting solutions were plated on NA plates supplemented with Rif (for the wild type and mutants). Each diluted homogenate was plated on three plates, respectively. The number of bacterial colonies on these plates was calculated after 2 days of incubation at $28^{\circ} \mathrm{C}$. The experiment was performed three times.

HR assay. The HR (hypersensitive response, a programmed cell death) assay was performed as described previously (Zou et al. 2006). Briefly, the wild-type (Rs105) and mutant strains were cultured in $\mathrm{NB}$ medium at $28^{\circ} \mathrm{C}$ and $200 \mathrm{rpm}$. All the tested strains were cultured to a concentration of $\mathrm{OD}_{600 \mathrm{~nm}}=1.0$ and centrifuged at $6,000 \mathrm{rpm}$ to remove the culture medium. Cells were washed twice with sterile $d_{d H_{2}} \mathrm{O}$ and were suspended in sterile $d_{d H_{2}} \mathrm{O}$ with $\mathrm{OD}_{600 \mathrm{~nm}}$ adjusted to 0.5 . The bacterial suspension was infiltrated into the leaves of nonhost plant tobacco (Nicotiana tabacum L. 'Samsun') using needleless syringes. HR was observed and documented after 24 to $48 \mathrm{~h}$ of infiltration. The experiment was repeated three times.

Growth determination of $\Delta t r p R$ and $\Delta h i s B$ in XOM3 medium supplemented with different concentrations of 
L-histidine. To confirm that $\operatorname{trpR}$ and hisB in $X$. oryzae pv. oryzicola were involved in histidine metabolism, we tested the growth rate of $\Delta t r p R$ and $\Delta$ hisB in XOM3 medium, which were supplemented with different concentrations of L-histidine. In brief, $X$. oryzae pv. oryzicola strains were grown in NB broth at $28^{\circ} \mathrm{C}$ with shaking at $200 \mathrm{rpm}$. Cells were pelleted at the early logarithmic phase $\left(\mathrm{OD}_{600 \mathrm{~nm}}=0.5\right)$ by centrifugation at $6,000 \mathrm{rpm}$. Cells were washed twice with sterile ddH2O and were suspended in an equal volume of sterile $\mathrm{ddH}_{2} \mathrm{O}$. Then, a $300 \mu \mathrm{l}$ of suspension was added into $30 \mathrm{ml}$ of XOM3 medium supplemented with L-histidine (Sigma) at concentrations of $0 \mu \mathrm{M}, 50 \mu \mathrm{M}, 250 \mu \mathrm{M}$, and $1 \mathrm{mM}$. All inoculated broths were grown at $28^{\circ} \mathrm{C}$ with shaking at $200 \mathrm{rpm}$, and the $\mathrm{OD}_{600 \mathrm{~nm}}$ value was determined every 8 or $12 \mathrm{~h}$ until bacterial growth reached the stationary stage.

Extraction and quantitative determination of the xanthomonadins. The extraction and determination of the xanthomonadins were performed as described previously in $X$. campestris pv. campestris (He et al. 2011). Briefly, X. oryzae pv. oryzicola wild-type strain and its derivative strains were grown in NB broth at $28^{\circ} \mathrm{C}$ with shaking at $200 \mathrm{rpm}$ overnight. Two hundred-microliter aliquots of cells were transferred to $20 \mathrm{ml}$ of freshly XOM3 broth supplemented with L-histidine and then cultured until the stationary phase $\mathrm{OD}_{600 \mathrm{~nm}}$ reached 2.0. Cells were collected by centrifugation at $10,000 \times g$ for $30 \mathrm{~min}$ and were resuspended in $1 \mathrm{ml}$ of methanol. The suspension was shaken for $5 \mathrm{~min}$ at room temperature. Finally, a 100- $\mu$ l aliquot of each extract was analyzed at an optical density of $445 \mathrm{~nm}\left(\mathrm{OD}_{445 \mathrm{~nm}}\right)$. The $\mathrm{OD}_{445 \mathrm{~nm}}$ values obtained were used to determine the amount of xanthomonadins produced by each strain. The assay was performed three times, and the averages and standard deviations were calculated for each experiment.

Real-time PCR. Real-time PCR was performed according to a recent report in $X$. oryzae pv. oryzae (Liang et al. 2018), with minor modification. In brief, the experimental strains were grown in $\mathrm{NB}$ at $28^{\circ} \mathrm{C}$ with shaking at $200 \mathrm{rpm}$ and cultured to $\mathrm{OD}_{600 \mathrm{~nm}}=$ 1.0 , and centrifuged at $6,000 \mathrm{rpm}$ to remove culture medium. Cells were washed twice with $\operatorname{ddH}_{2} \mathrm{O}$, and then cell pellets were suspended in an equal volume of XOM3 broth. Cells of each strain were collected from XOM3 broth after treatment with L-histidine concentrations of $0 \mu \mathrm{M}, 250 \mu \mathrm{M}$, and $1 \mathrm{mM}$ for $3 \mathrm{~h}$. RNA was isolated from $X$. oryzae pv. oryzicola under the guidance of instructions of the E.Z.N.A. Bacterial RNA Kit (OMEGA). According to the instructions of PrimeScript RT Reagent Kit (TaKaRa), RNA samples were initially treated with RNase inhibitors and DNaseI to remove gDNA. RNA integrity was then confirmed through electrophoresis by using $1.2 \%$ agarose gels, then $2 \mu \mathrm{g}$ of each RNA sample was used to synthesize cDNA. The cDNA was subjected to quantitative real-time reverse transcription PCR (qRT-PCR) by using SYBR Premix EX Tag (TaKaRa) in an ABI PRISM 7500 Real-Time PCR System (Applied Biosystems), and 16S rRNA was used as an endogenous control. The primer sequences used in this assay are listed in Supplementary Table S3. The experiment was performed three times.

\section{RESULTS}

Analysis of the his operon in Xanthomonas. Using a BLASTP search, we analyzed the his operon in X. oryzae pv. oryzicola and other related species. As shown in Figure 1A, the his operon consists of eight genes (hisA, $-B,-C,-D,-F,-G,-H$, and $-I E$ ) in the available genome of $X$. oryzae pv. oryzicola BLS256. Meanwhile, in X. oryzae pv. oryzicola, trpR, a gene upstream of $h i s G$, encodes a transcriptional regulator. The $\operatorname{trp} R$ gene was considered as part of the his operon. Sequencing analysis showed that the nine genes of his operon share the same transcriptional direction and are highly conserved in $X$. oryzae pv. oryzae, $X$. axonopodis pv. citri, $X$. campestris pv. campestris, and $X$. campestris pv. vesicatoria. The amino acid identity of each of the nine genes is above $80 \%$ between these Xanthomonas strains. These results suggest that the his operon may encode conserved functions in Xanthomonas spp. Meanwhile, it showed that the metabolic pathway of direct histidine biosynthesis from PRPP to L-histidine needed the participation of the enzymes encoded by the genes of his $A,-B,-C,-D,-F,-G,-H$, and $-I E$ in $X$. oryzae pv. oryzicola (Fig. 1B).

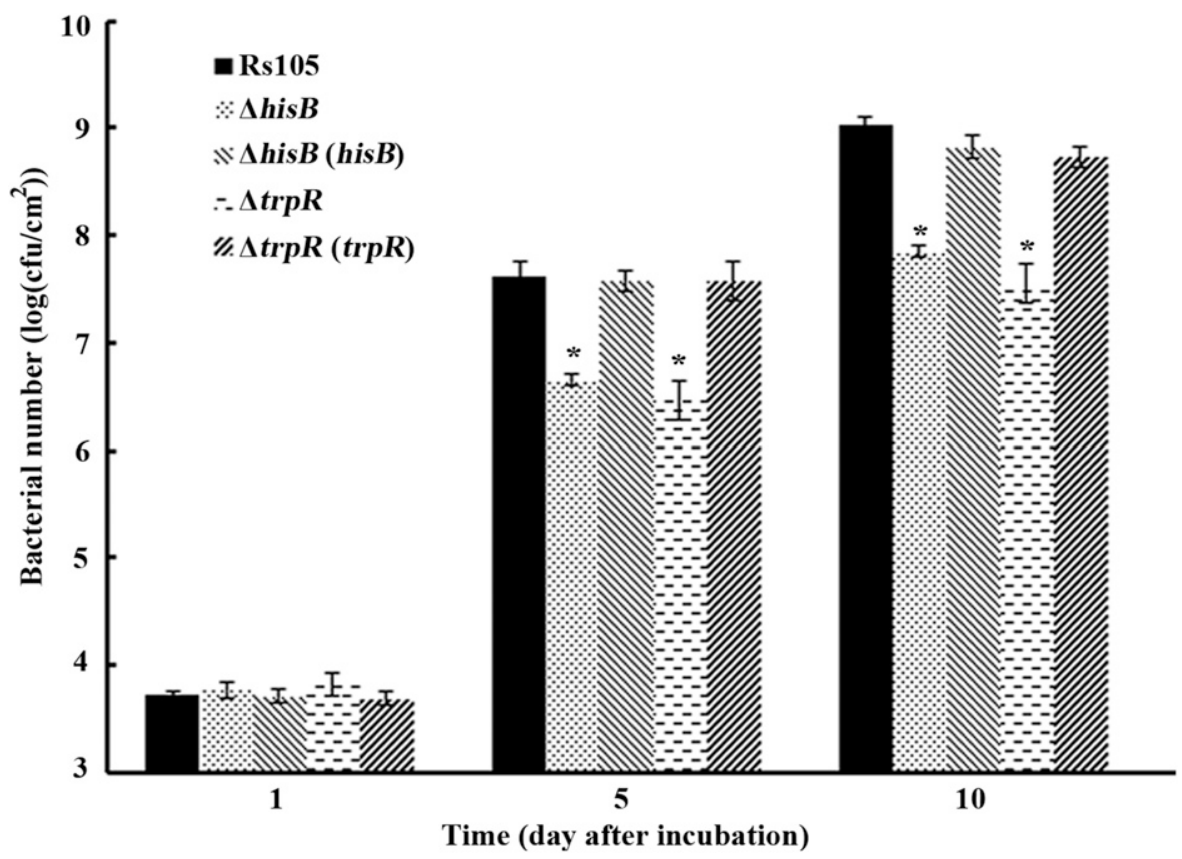

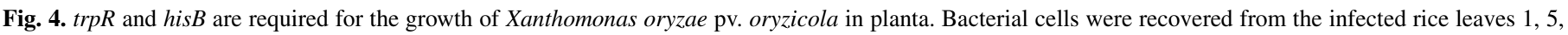

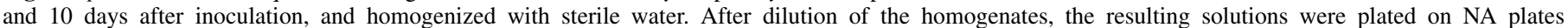

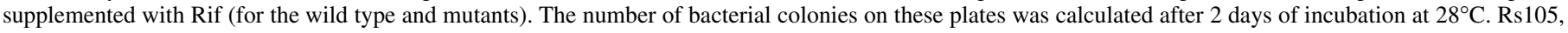

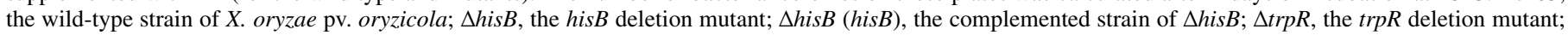

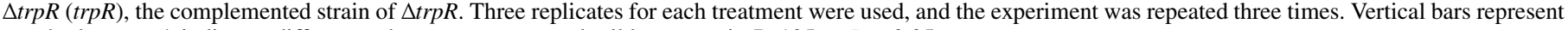
standard errors. * indicates differences between mutant and wild-type strain Rs 105 at $P=0.05$. 
his operon is essential for histidine biosynthesis in $X$. oryzae pv. oryzicola. To confirm that the his operon in X. oryzae pv. oryzicola was involved in histidine biosynthesis, we tested the growth state of the mutants in XOM3 with different concentrations of L-histidine. The mutants, $\Delta \operatorname{trp} R, \Delta$ hisA, $\Delta$ his $B, \Delta$ his $C, \Delta h i s D$, $\Delta$ hisIE, $\Delta$ hisF, $\Delta$ his $G$, and $\Delta$ hisH, were obtained as a result of the deletion of one gene of the his operon. Compared with the wild type which grew well in XOM3 medium without L-histidine, significant
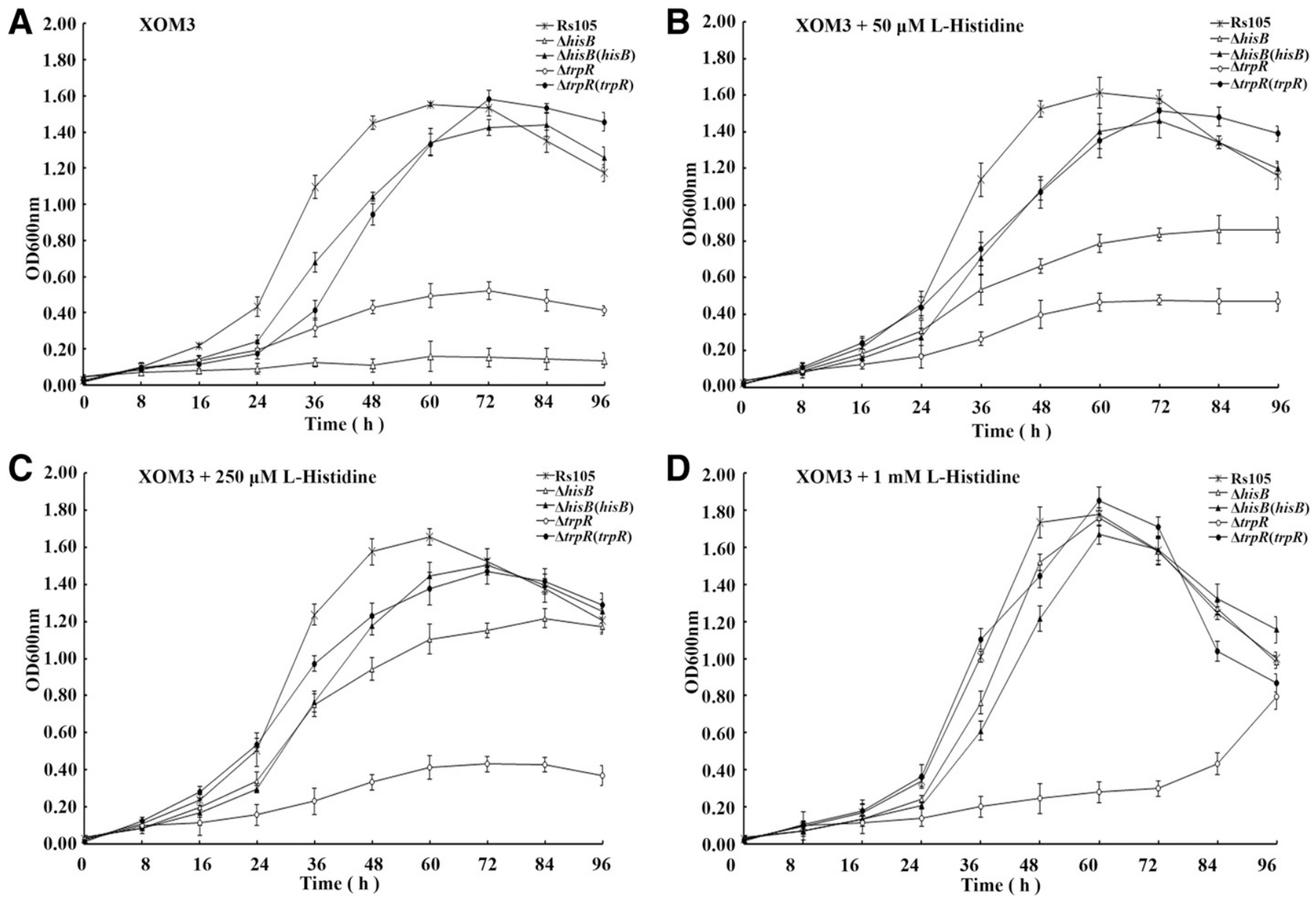

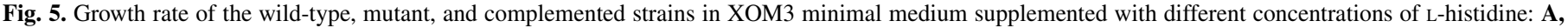

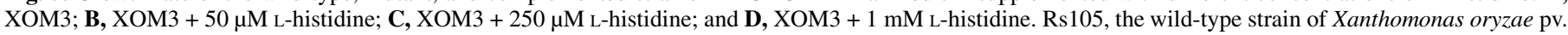

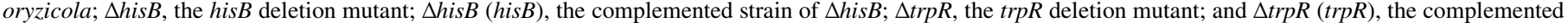

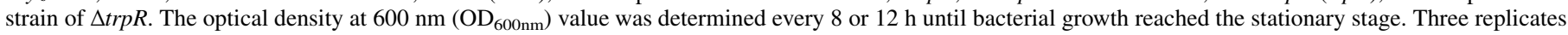
for each treatment were used, and the experiment was repeated three times. Vertical bars represent standard errors.

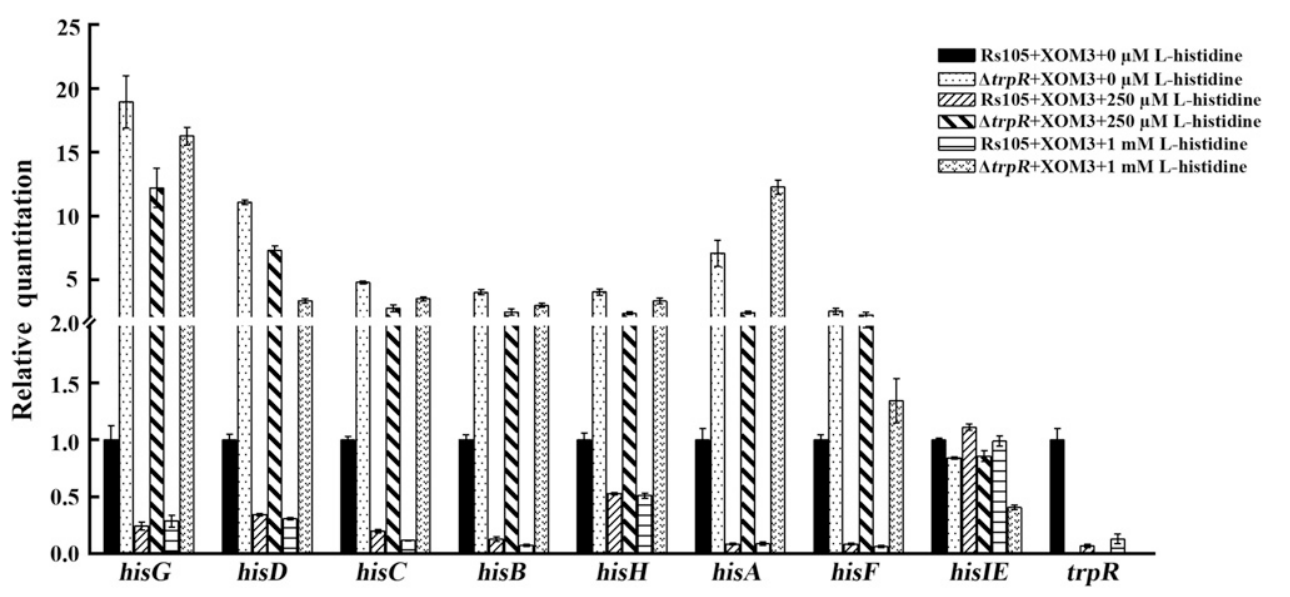

Fig. 6. $\operatorname{trp} R$ negatively regulates the expression of his $G,-D,-C,-B,-H,-A,-F$, and the transcriptions of his $G,-D,-C,-B,-H,-A,-F$, and trpR are inhibited by histidine. RNA was isolated from the cells of each strain, which were collected from XOM3 broth treated with $0 \mu \mathrm{M}, 250 \mu \mathrm{M}$, and $1 \mathrm{mM} \mathrm{L}$-histidine for $3 \mathrm{~h}$. Quantitative real-time PCR was performed to analyze the expression levels of genes. Rs105, the wild-type strain of Xanthomonas oryzae pv. oryzicola; $\Delta$ trpR, the $\operatorname{trp} R$ deletion mutant. Data were the means \pm standard deviations of triplicate measurements from a representative experiment, and similar results were reported from two other independent experiments. Vertical bars represent standard errors. 
growth inhibition was observed in the his operon mutants (Fig. 2): single mutants of the eight his operon genes ( $\Delta$ hisA, $\Delta$ hisB, $\Delta$ hisC, $\Delta$ hisD, $\Delta$ hisIE, $\Delta$ hisF, $\Delta h i s G$, and $\Delta h i s H$ ) showed no growth in XOM3 medium without supplementation of L-histidine after 5 days incubation at $28^{\circ} \mathrm{C}$ and one mutant, $\Delta \operatorname{trp} R$, showed significantly reduced growth. The inhibited growth in the his operon mutants could be restored by supplementing the XOM3 medium with $50 \mu \mathrm{M}$ L-histidine. $\Delta$ his $B$ mutant appears as a white dot in the plate surface, whereas the wild-type bacteria and other mutant strains showed intense yellow color. This phenomenon showed that the hisB mutant lacked yellow pigmentation. In XOM3 media supplemented with $250 \mu \mathrm{M}$ and $1 \mathrm{mM}$ L-histidine, the growth states of all the mutants were similar in comparison with the wild-type strain. It must be noted that wild-type and mutant bacteria grew as single dots except for mutant $\Delta t r p R$ (Fig. 2). The bacterial growth was restored in the corresponding complemented strains of the mutants of $\operatorname{trp} R$ and hisB (Supplementary Fig. S1). These results indicated that the his operon was involved in histidine biosynthesis in X. oryzae pv. oryzicola.

$\operatorname{trpR}$ and $h i s B$ are required for the full virulence and growth of $X$. oryzae pv. oryzicola in planta and the his operon is not necessary for triggering the HR in nonhost (plant) tobacco. To determine whether his operon genes played a role in the virulence of $X$. oryzae pv. oryzicola, we compared the virulence of the mutants with wild type by injecting bacterial cells into the rice leaves using the inoculation concentration of $\mathrm{OD}_{600 \mathrm{~nm}}=0.5$ (Qian et al. 2013a; Zhao et al. 2012). As shown in Figure $3 \mathrm{~A}$ and B, all mutants exhibited decreased virulence in comparison with the wild-type Rs105, as reflected by the reduced length of water-soaking lesion symptoms. Meanwhile, the mutants of $\operatorname{trpR}$ and his $B$ exhibited a significant reduction in virulence, whereas their corresponding complemented strains retained almost full wild-type ability in this function. These results indicated that the his operon was required for bacterial endophytic life style. Since hisB mutant showed a stronger phenotype than other his genes mutants, and the hisB gene could have another implication in pathogenicity. Phenotype associated with trp mutant could also be associated with other virulence aspect.

In order to explore whether the roles of $\operatorname{trpR}$ and his $B$ in virulence were related with the proliferation of $X$. oryzae pv. oryzicola on host rice, we measured the growth ability of the mutants of $\operatorname{trp} R$ and hisB in the infected rice leaves. The bacterial cells were recovered from the infected rice leaves 1,5 , and 10 days after inoculation. As shown in Figure $4, \Delta t r p R$ and $\Delta h i s B$ exhibited a significant decrease in cell numbers compared with the wild-type strain when were recovered
A

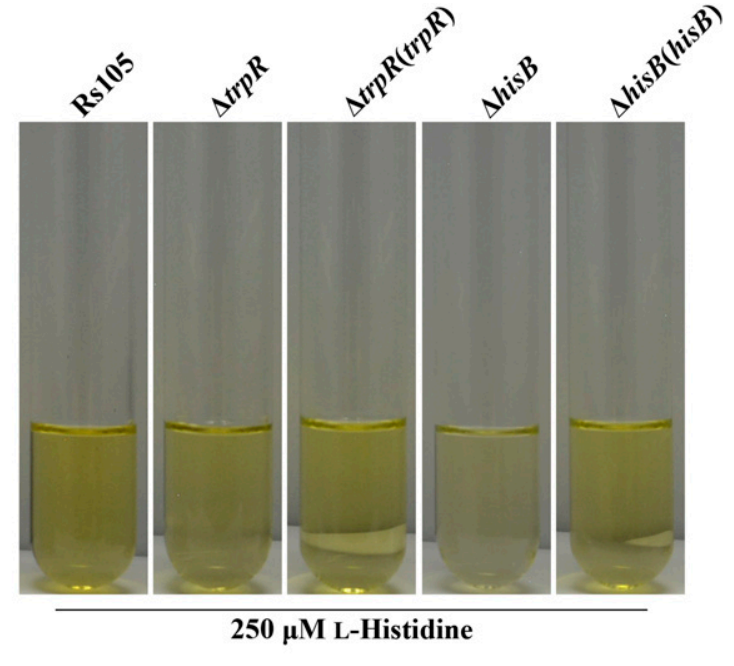

C

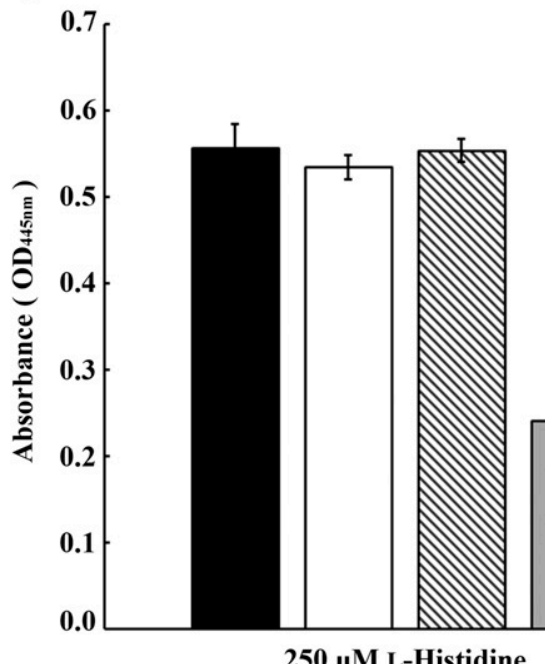

$250 \mu \mathrm{M}$ L-Histidine
B
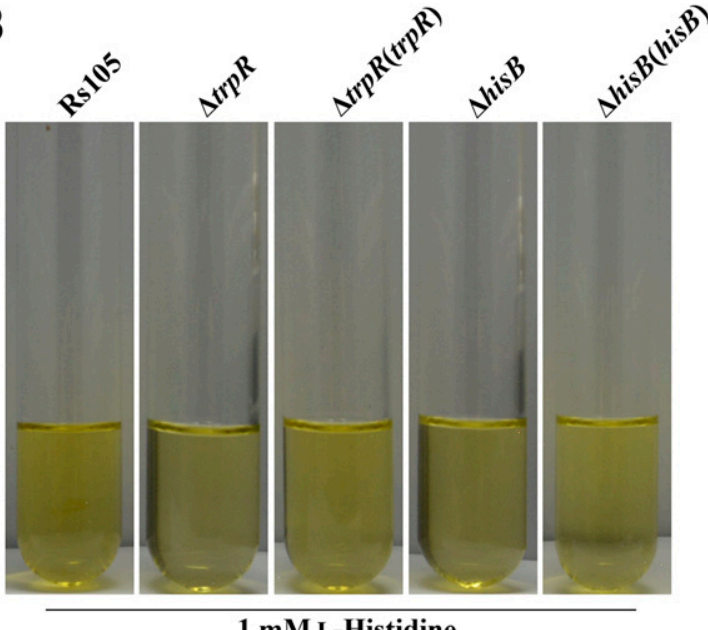

$\square \operatorname{Rs} 105$

$\mathrm{a} \Delta \mathrm{trpR}$

$\Delta \Delta \operatorname{trpR}(\operatorname{trpR})$

a $\Delta$ hisB

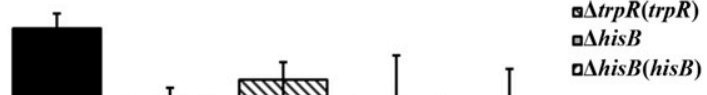

1 mM L-Histidine

Fig. 7. Xanthomonadins production assay of the wild-type, mutant, and complemented strains. A, Representative results of extraction of xanthomonadins in Xanthomonas oryzae pv. oryzicola strains cultured in XOM3 broth supplemented with $250 \mu \mathrm{M}$ L-histidine. B, Representative results of extraction of xanthomonadins pigment in $X$. oryzae pv. oryzicola strains cultured in XOM3 broth supplemented with $1 \mathrm{mM}$ L-histidine. C, Calculated data of xanthomonadins production in $X$. oryzae pv. oryzicola strains. Rs105, the wild-type strain of $X$. oryzae pv. oryzicola; $\Delta$ hisB, the hisB deletion mutant; $\Delta$ hisB (hisB), the complemented strain of $\Delta h i s B ; \Delta \operatorname{trp} R$, the $\operatorname{trp} R$ deletion mutant; and $\Delta \operatorname{trpR}(\operatorname{trp} R)$, the complemented strain of $\Delta \operatorname{trp} R$. Results were obtained in three independent experiments. Vertical bars represent standard errors. 
after 5 and 10 days. Meanwhile, the complemented strains of trpR and his $B$ mutants exhibited a wild-type level in this function. These results suggested that mutations of $\operatorname{trp} R$ and his $B$ reduced the growth ability of $X$. oryzae pv. oryzicola in planta.

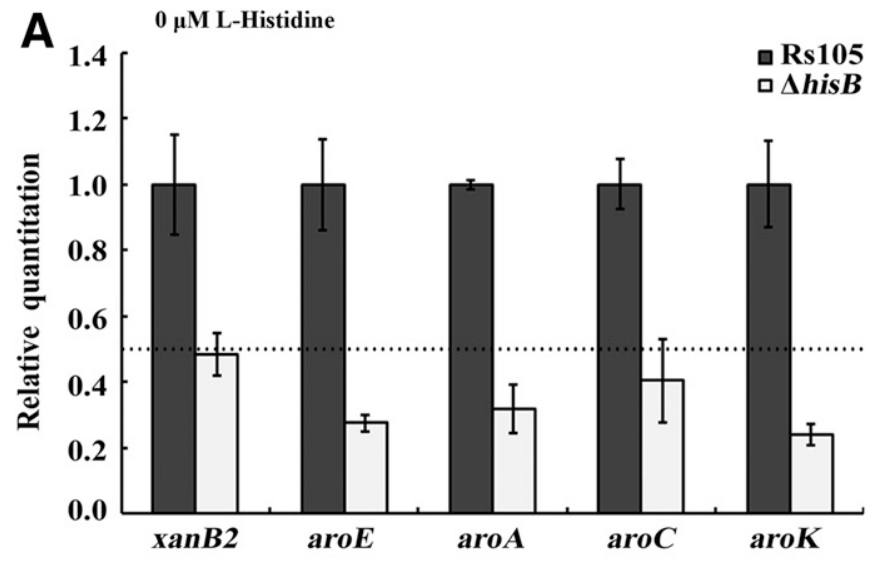

B

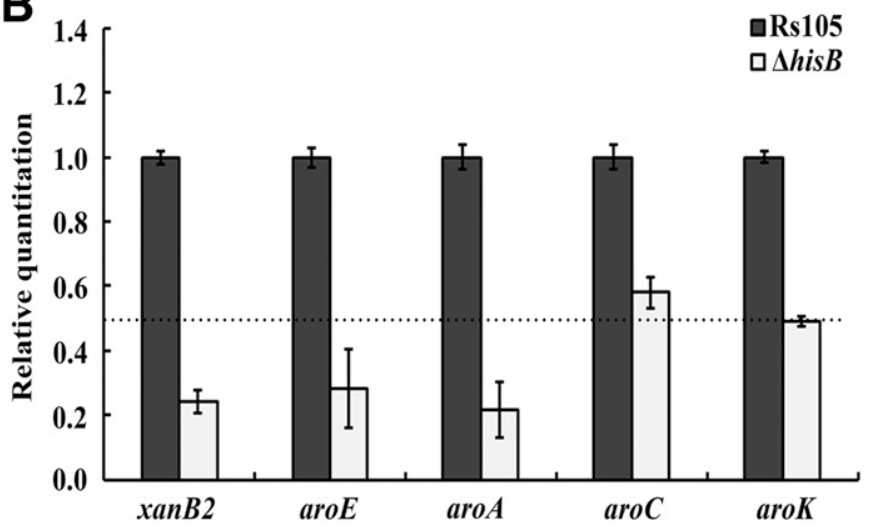

C $1 \mathrm{mM}$ L-Histidine

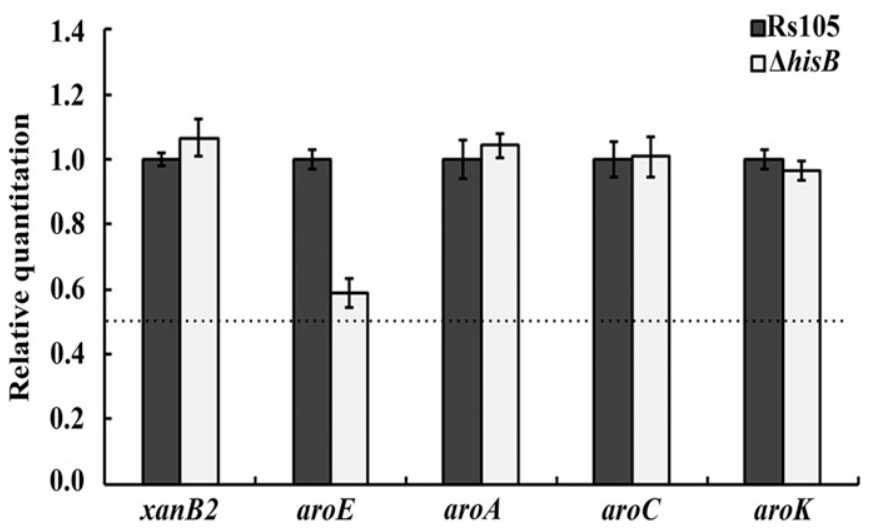

Fig. 8. Transcription determination of five known pigment-associated genes of Xanthomonas oryzae pv. oryzicola in the hisB deletion mutant and wild-type strain. A, After treatment with $0 \mu \mathrm{M}$ L-histidine for $3 \mathrm{~h}$, RNA was isolated from the wild-type strain and mutant of hisB. Quantitative real-time PCR was performed to analyze the difference in expression levels of genes (xanB2, aroE, $\operatorname{aro} A$, aro $C$, and $\operatorname{aroK}$ ) between the wild-type and $\triangle$ hisB mutant. B, After treatment with $250 \mu \mathrm{M}$ L-histidine for $3 \mathrm{~h}$, RNA was isolated from the wild-type strain and mutant of hisB. Quantitative real-time PCR was performed to analyze the difference in expression levels of genes (xanB2, aroE, aroA, aroC, and aroK) between the wild-type and $\Delta$ hisB mutant. C, After treatment with $1 \mathrm{mM} \mathrm{L-}$ histidine for $3 \mathrm{~h}$, RNA was isolated from the wild-type strain and the mutant of hisB. Quantitative real-time PCR was performed to analyze the difference in expression levels of genes ( $x a n B 2$, aroE, aroA, aro $C$, and $\operatorname{aroK}$ ) between the wildtype and $\Delta h i s B$ mutant. Data were the means \pm standard deviations of triplicate measurements from a representative experiment, and similar data were reported from two other independent experiments. Vertical bars represent standard error. Black dashed line indicates a twofold decrease in the transcription level.
To determine whether the virulence reduction was because of the reduced ability to trigger plant immunity, we tested the ability to trigger HR in the his operon mutants. All mutants produced similar level of HR compared with the wild-type, indicating that his operon was not involved in the triggering of HR in nonhost (plant) tobacco.

Growth rate of $\operatorname{trpR}$ and hisB mutants in XOM3 supplemented with different concentrations of L-histidine. To confirm the effects of $\operatorname{trpR}$ and hisB on histidine biosynthesis in $X$. oryzae pv. oryzicola, we measured the growth rate of wild-type strain Rs105, the trpR mutant $(\Delta \operatorname{trpR})$, the hisB mutant $(\Delta h i s B)$, and their corresponding complemented strains in XOM3 supplemented with different concentrations of L-histidine. As shown in Figure 5A, $\Delta \operatorname{trpR}$ and $\Delta$ his $B$ displayed reduced growth in XOM3 supplemented with $0 \mu \mathrm{M}$ L-histidine compared with wild-type strain and corresponding complemented strain. The growth ability of hisB mutant in XOM3 was partially restored by supplementing $50 \mu \mathrm{M}$ and $250 \mu \mathrm{M}$ L-histidine into the growth medium, whereas the growth ability of the trpR mutant remained almost unchanged (Fig. $5 \mathrm{~B}$ and $\mathrm{C})$. When the concentration of histidine in XOM3 reached $1 \mathrm{mM}$, the growth rate of $\Delta h i s B$ could be completely restored to the level of the wild-type strain. Using the same conditions, the growth ability of $\triangle t r p R$ was partially restored at $96 \mathrm{~h}$ (Fig. 5D). These results supported the assertion that $\operatorname{trp} R$ and $h i s B$ were necessary for histidine biosynthesis in $X$. oryzae pv. oryzicola.

trpR negatively regulates the expression of his $G,-D,-C$, $-B,-H,-A$, and $-F$, and the transcription of $h i s G,-D,-C,-B$, $-H,-A,-F$, and $\operatorname{trp} R$ is inhibited by histidine. Bioinformatics analysis shows that the $\operatorname{trp} R$ is located upstream of his $G$ and encodes a transcriptional regulator. In order to investigate the effect of $\operatorname{trp} R$ on the transcriptional level of other genes of the his operon, a quantitative real-time PCR was performed comparing between the wild-type and $\triangle \operatorname{trp} R$ mutant with/without L-histidine. Results showed that the transcription of his $G,-D,-C,-B,-H,-A$, and $-F$ in $\Delta \operatorname{trp} R$ was higher than in the wild-type strain with $0 \mu \mathrm{M}$ L-histidine, whereas the expression level of hisIE in $\Delta t r p R$ was not significantly different when compared with gene expression of the wild-type strain in same conditions (Fig. 6). After treatment with $250 \mu \mathrm{M}$ and $1 \mathrm{mM}$ L-histidine for $3 \mathrm{~h}$, we could also observe that the transcription of his $G,-D,-C,-B,-H,-A$, and $-F$ in $\Delta t r p R$ was higher in comparison with genes expression of the wild-type strain in the same conditions (Fig. 6). Meanwhile, results showed that the transcription of his $G,-D,-\mathrm{C},-B,-H,-A$, and $-F$ and $\operatorname{trp} R$ in wildtype strains treated with $250 \mu \mathrm{M}$ and $1 \mathrm{mM}$ L-histidine was lower than in the wild-type strain treated with $0 \mu \mathrm{M}$ L-histidine, whereas the expression level of gene hisIE was not significantly different among wild-type strains treated by different concentrations of histidine (Fig. 6). These results indicated that $\operatorname{trp} R$ negatively regulates the expression of $h i s G,-D,-C,-B,-H,-A$, and $-F$, and the transcription of his $G,-D,-C,-B,-H,-A$, and $-F$ and $\operatorname{trp} R$ is inhibited by histidine.

Mutation of hisB in $X$. oryzae pv. oryzicola impairs xanthomonadins production. The results in Figure 2 showed that the hisB mutant phenotypically appeared as a clear white colony as opposed to the yellow colony morphology developed by the wild type. As the yellow pigment produced by $X$. oryzae pv. oryzicola is the result of xanthomonadins production, we hypothesized that that his $B$ might be related to xanthomonadins production in $X$. oryzae pv. oryzicola. To test this hypothesis, xanthomonadins were extracted from the wild-type, the his $B$ mutant and the complementation strain $\Delta h i s B$ (hisB) in XOM3 supplemented with different concentrations of L-histidine. Considering that $\Delta h i s B$ growth at $50 \mu \mathrm{M}$ concentration of L-histidine was too slow to collect bacteria, we quantified the xanthomonadins production at $250 \mu \mathrm{M}$ and $1 \mathrm{mM}$ L-histidine. This experiment was also carried out with the trpR mutant and its corresponding complemented strain $\Delta \operatorname{trpR}(\operatorname{trpR})$. As shown in Figure 7A and C, the extracted xanthomonadins from $\Delta h i s B$ were lighter in color, and 
quantitative analysis showed that the xanthomonadins production level of $\Delta h i s B$ was significantly decreased compared with the wildtype strain; however, the xanthomonadins production level of $\Delta$ his $B$ could be restored to wild-type level in XOM3 supplemented with $1 \mathrm{mM}$ L-histidine (Fig. 7B and C). Xanthomonadins production level of $\Delta t r p R$ did not significantly decrease compared with the wild-type strain. These results indicated that $h i s B$ played a role in xanthomonadins production in $X$. oryzae pv. oryzicola.

Transcriptional expression of five known pigmentassociated genes is reduced in the his $B$ deletion mutant. To investigate the mechanism of his $B$ in affecting xanthomonadins production, transcriptional expression of five pigment-associated genes, including $x a n B 2$ (encodes bifunctional chorismatase), aroE (encodes shikimate 5-dehydrogenase), aroA (encodes 3phosphoshikimate1-carboxyvinyltransferase), aroC (encodes chorismate synthase), and $\operatorname{aroK}$ (encodes shikimate kinase) (Guo et al. 2012; Kim et al. 2015; Song et al. 2012; Wang et al. 2007; Zhou et al. 2013a, b) was compared in $\Delta$ hisB and wild type strains cultured in XOM3 supplemented with different concentrations of L-histidine. This was done to investigate whether hisB had a regulatory role for transcriptional expression of these known pigment-associated genes in $X$. oryzae pv. oryzicola. The mutation of hisB reduced the transcriptional expression of five known pigment-associated genes ( $x a n B 2$, aroE, aroA, aroC, and $\operatorname{aroK}$ ) in XOM3 supplemented with 0 and $250 \mu \mathrm{M}$ L-histidine (Fig. 8A and B). All selected genes were restored to wild-type expression levels in XOM3 supplemented with $1 \mathrm{mM}$ L-histidine (Fig. 8C).

aroE is required for xanthomonadins production and virulence of $X$. oryzae $\mathrm{pv}$. oryzicola and the aro $E$ is not necessary for triggering the HR in nonhost (plant) tobacco. To test whether the pigment-associated gene in X. oryzae pv. oryzicola involved in xanthomonadins production and virulence, we constructed the deletion mutant of aroE. As shown in Figure 9A, the mutant of aroE showed white color in the plate surface, while the wild-type Rs 105 and its corresponding complemented strain showed yellow color. Meanwhile, the mutant of aroE exhibited a significant reduction in virulence compared with wild type strain in this function, whereas its corresponding complemented strain retained wild-type ability in this function (Fig. 9B and C). This result indicated that $\operatorname{aro} E$ was required for xanthomonadins production and virulence $X$. oryzae pv. oryzicola. As shown in Supplementary Figure S2, the mutant of aroE produced similar level of HR compared with the wild-type, indicating that the aroE was not involved in the triggering of HR in nonhost (plant) tobacco.

\section{DISCUSSION}

In this study, nine mutants of histidine biosynthesis genes were constructed. Auxotrophic assays confirmed that the his operon was involved in histidine biosynthesis in $X$. oryzae pv. oryzicola.

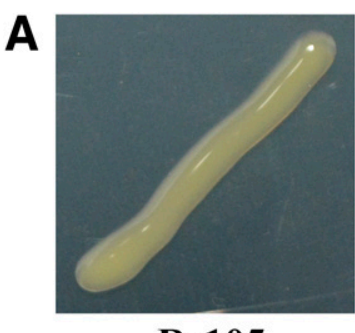

Rs105

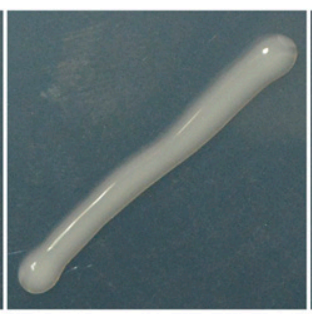

DaroE

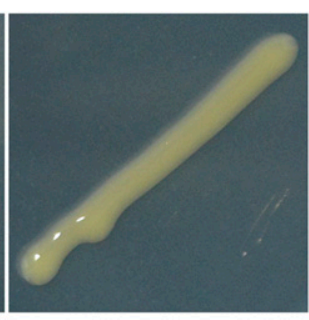

$\Delta a r o E(a r o E)$

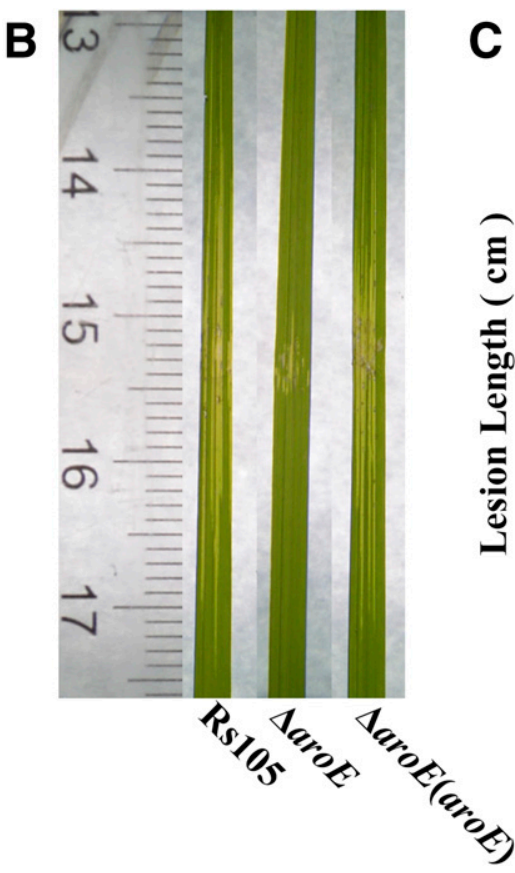

C

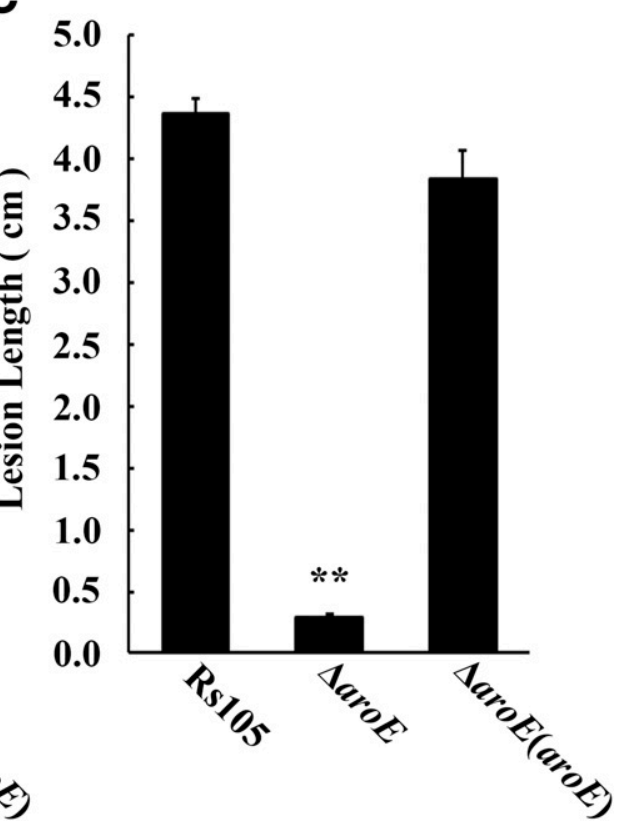

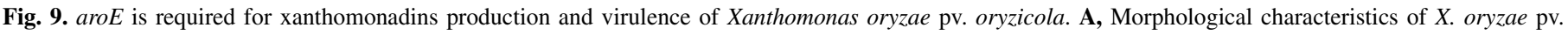

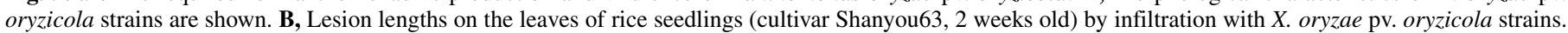

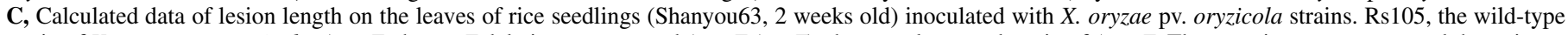

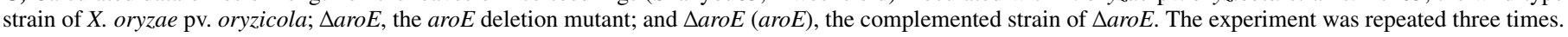

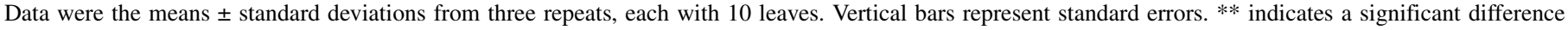
between mutant and the wild-type Rs105 at $P=0.01$. 
Mutations of $\operatorname{trpR}$ and hisB impaired the virulence and growth of $X$. oryzae pv. oryzicola in planta. Meanwhile, the hisB gene was required for xanthomonadins production in $X$. oryzae pv. oryzicola. It also demonstrated that the $\operatorname{trp} R$ gene could negatively regulate the expression of his $G,-D,-C,-B,-H,-A$, and $-F$, while transcriptions of his $G,-D,-C,-B,-H,-A,-F$, and trpR could be inhibited by histidine.

The his operon was highly conserved both in its genomic organization and gene function among different Xanthomonas (Fig. 1). Previous study have shown that HisB and HisIE were both histidine biosynthesis bifunctional proteins, but they had different functions and participated in different reactions in histidine biosynthesis (Alifano et al. 1996). The bifunctional HisIE enzyme, which catalyzes the second and third steps of the histidine biosynthesis pathway, is encoded by hisIE and is involved in the activities of two enzymes, namely, phosphoribosyl-ATP pyrophosphatase and phosphoribosyl-AMP cyclohydrolase (Kulis-Horn et al. 2014). hisB encodes HisB enzyme, which is a bifunctional enzyme implicated in the imidazoleglycerol-phosphate dehydratase activity, for the sixth step of biosynthesis, and the histidinol-phosphate phosphatase activity, for the eighth step of biosynthesis (Kulis-Horn et al. 2014). Results obtained during this study have shown that his $B$ gene was required for virulence and xanthomonadins production in $X$. oryzae pv. oryzicola, but hisIE was not required for these functions. Moreover, results showed that the expression of hisB was negatively regulated by $\operatorname{trp} R$ and inhibited by histidine, but the expression of hisIE was not significantly affected by $\operatorname{trp} R$ and histidine (Fig. 6). Further investigation is needed to understand the role of hisIE in X. oryzae pv. oryzicola.

All nine mutants of the his operon in $X$. oryzae pv. oryzicola could not grow well in XOM3 without histidine and their growth could be partially or completely restored by exogenous addition of histidine (Fig. 2). This result confirmed that the conserved his operon was involved in histidine biosynthesis. Interestingly, although nine genes in the his operon were necessary for histidine biosynthesis, only the genes of $\operatorname{trpR}$ and hisB were strictly required for the virulence of $X$. oryzae pv. oryzicola (Fig. 3). Meanwhile, mutations of $t r p R$ and his $B$ reduced the in planta growth ability of $X$. oryzae $\mathrm{pv}$. oryzicola (Fig. 4). However, we found that the his operon did not impair HR, indicating that the contribution of the histidine synthesis pathway to virulence might be not related to HR in X. oryzae pv. oryzicola. These results indicated that the decrease of hisB or trpR in symptoms development was associated with the reduced in planta growth, and this was supported by the fact that the his operon did not impair HR response. Finally, we compared the protease activity of wild-type Rs105 and mutants, but no visible alterations in the hydrolytic zones were detected around the bacterial colonies of the mutants and the wild- type strain. Determination of extracellular protease activity indicated that the his operon was independent of protease activity (data not shown).

Bioinformatics analysis showed that $\operatorname{trpR}$ gene which is located upstream of his $G$ encodes a transcriptional regulator (Fig. 1). In this study, the mutant of trpR could not grow well in XOM3 medium with $0 \mu \mathrm{ML}$-histidine compared with the wild type, and the growth of $\operatorname{trp} R$ could not be completely restored by exogenous addition of histidine (Fig. 2). Meanwhile, our data revealed that $\operatorname{trp} R$ could negatively regulate the expression of his $A,-B,-C,-D,-F,-G$, and $-H$ (Fig. 6). Thus, we speculated that the overexpression of his operon in $\operatorname{trp} R$ mutant was toxic for the cell, and possible toxic effect could explain why the virulence and bacterial growth in planta of the $\operatorname{trp} R$ mutant decreased. The transcription of his $G,-D,-\mathrm{C},-B,-H,-A$, and $-F$ was inhibited by histidine (Fig. 6). This indicated that histidine could feedback histidine biosynthetic pathways: when external sources of histidine are available, the histidine biosynthesis genes will not be turned on. Moreover, the transcription of $\operatorname{trpR}$ which acted as a transcriptional repressor to negatively regulate the expression of other genes in the his operon could also be inhibited by histidine. The roles of $\operatorname{trpR}$ of $X$. oryzae pv. oryzicola need to be further investigated.
Most Xanthomonas bacteria produce membrane-bound yellow pigments known as xanthomonadins (Starr 1981). Xanthomonadins are not only a useful chemotaxonomic and diagnostic marker for Xanthomonas spp., but it can also protect the pathogen from photobiological and peroxidation damages in epiphytic survival and in bacterial systemic infections (He et al. 2011; Jenkins and Starr 1982; Poplawsky et al. 2000; Rajagopal et al. 1997; Schaad and Stall 1988; Starr and Stephens 1964).

In this study, we found that deletion of his $B$ significantly reduced the xanthomonadins production compared with the wild-type strain (Fig. 7A and C). Xanthomonadins are closely related to the pathogenicity of Xanthomonas. In vitro inoculation experiments showed that the pathogenicity of pigment-deficient mutants of $X$. oryzae pv. oryzae or X. campestris pv. campestris is decreased (Goel et al. 2001; Poplawsky and Chun 1998). In the present study, the mutant of hisB not only reduced the xanthomonadins production but also impaired the bacterial virulence of $X$. oryzae pv. oryzicola. This finding indicated that xanthomonadins were also closely related to the pathogenicity of $X$. oryzae pv. oryzicola. Xanthomonadin biosynthesis is based on the shikimate pathway (He et al. 2011; Jenkins and Starr 1982; Poplawsky et al. 2000; Rajagopal et al. 1997). Our results implied that hisB might be related to the shikimate pathway. To test this hypothesis, we identified the transcriptional expression levels of five key shikimate pathway-related genes, such as aroA (XOC_2876, encodes 3-phosphoshikimate1-carboxyvinyltransferase), aroC (XOC_2961, encodes chorismate synthase), aroE (XOC_ 4333, encodes shikimate 5-dehydrogenase), aroK (XOC_1390, encodes shikimate kinase), and XanB2 (XOC_0424, encodes shikimate 5-dehydrogenase) (Kim et al. 2015; Song et al. 2012; Zhou et al. $2013 \mathrm{~b}$ ), in $\Delta$ hisB and wild type. As shown in Figure 8, the deletion of his $B$ reduced the transcriptional expression level of shikimate pathway-related genes (xanB2, aroE, aro $A$, aro $C$, and $\operatorname{aroK}$ ). This result indicated that his $B$ might be acting through the shikimate pathway to influence the xanthomonadins production. Meanwhile, using the aroE mutant, we demonstrated that one of shikimate pathway-related genes, aroE, played an important role in xanthomonadin production and virulence in $X$. oryzae pv. oryzicola, proving that xanthomonadin was involved in the virulence of $X$. oryzae pv. oryzicola (Fig. 9). In addition, our study indicated that his $B$ might be linked to the shikimate pathway and the effect of hisB in the virulence was connected with xanthomonadins decrease in $X$. oryzae pv. oryzicola.

In summary, this study confirmed that the his operon is involved in histidine biosynthesis in $X$. oryzae pv. oryzicola. This study also demonstrated that genes $\operatorname{trp} R$ and $h i s B$ were required for virulence and bacterial growth in planta, and revealed that these two virulence-associated genes play roles in the regulation of histidine biosynthesis and in the xanthomonadins production, respectively. These findings extend our understanding of histidine metabolic pathways in Xanthomonas spp. and in bacterial species in general.

\section{LITERATURE CITED}

Alifano, P., Fani, R., Lio, P., Lazcano, A., Bazzicalupo, M., Carlomagno, M. S., and Bruni, C. B. 1996. Histidine biosynthetic pathway and genes: Structure, regulation, and evolution. Microbiol. Rev. 60:44-69.

Bochner, B. R., and Ames, B. N. 1982. ZTP (5-amino 4-imidazole carboxamide riboside $5^{\prime}$-triphosphate): A proposed alarmone for 10-formyl-tetrahydrofolate deficiency. Cell 29:929-937.

Carlomagno, M. S., Chiariotti, L., Alifano, P., Nappo, A. G., and Bruni, C. B. 1988. Structure and function of the Salmonella typhimurium and Escherichia coli K-12 histidine operons. J. Mol. Biol. 203:585-606.

Chapman, L. F., and Nester, E. W. 1969. Gene-enzyme relationships in histidine biosynthesis in Bacillus subtilis. J. Bacteriol. 97:1444-8.

Chiariotti, L., Alifano, P., Carlomagno, M. S., and Bruni, C. B. 1986. Nucleotide sequence of the Escherichia coli hisD gene and of the Escherichia coli and Salmonella typhimurium hisIE region. Mol. Gen. Genet. 203:382-388.

De Feyter, R., Kado, C. I., and Gabriel, D. W. 1990. Small, stable shuttle vectors for use in Xanthomonas. Gene 88:65-72.

Fani, R., Lio, P., and Lazcano, A. 1995. Molecular evolution of the histidine biosynthetic pathway. J. Mol. Evol. 41:760-774. 
Fani, R., Tamburini, E., Mori, E., Lazcano, A., Lio, P., Barberio, C., Casalone, E., Cavalieri, D., Perito, B., and Polsinelli, M. 1997. Paralogous histidine biosynthetic genes: Evolutionary analysis of the Saccharomyces cerevisiae HIS6 and HIS7 genes. Gene 197:9-17.

Fink, G. R. 1964. Gene-enzyme relations in histidine biosynthesis in yeast. Science 146:525-527.

Goel, A. K., Rajagopal, L., and Sonti, R. V. 2001. Pigment and virulence deficiencies associated with mutations in the $a r o E$ gene of Xanthomonas oryzae pv. oryzae. Appl. Environ. Microbiol. 67:245-250.

Guo, W., Cui, Y. P., Li, Y. R., Che, Y. Z., Yuan, L., Zou, L. F., Zou, H. S., and Chen, G. Y. 2012. Identification of seven Xanthomonas oryzae pv. oryzicola genes potentially involved in pathogenesis in rice. Microbiology-Sgm. 158: 505-518.

He, Y. W., Wu, J., Zhou, L., Yang, F., He, Y. Q., Jiang, B. L., Bai, L., Xu, Y., Deng, Z., Tang, J. L., and Zhang, L. H. 2011. Xanthomonas campestris diffusible factor is 3-hydroxybenzoic acid and is associated with xanthomonadin biosynthesis, cell viability, antioxidant activity, and systemic invasion. Mol. Plant-Microbe Interact. 24:948-957.

Jenkins, C. L., and Starr, M. P. 1982. The pigment of Xanthomonas populi is a nonbrominated aryl-heptaene belonging to xanthomonadin pigment group II. Curr. Microbiol. 7:195-198.

Jung, S., Chun, J. Y., Yim, S. H., Lee, S. S., Cheon, C. I., Song, E., and Lee, M. S. 2010. Transcriptional regulation of histidine biosynthesis genes in Corynebacterium glutamicum. Can. J. Microbiol. 56:178-187.

Jung, S. I., Han, M. S., Kwon, J. H., Cheon, C. I., Min, K. H., and Lee, M. S. 1998. Cloning of the histidine biosynthetic genes of Corynebacterium glutamicum: Organization and sequencing analysis of the hisA, impA, and hisF gene cluster. Biochem. Biophys. Res. Commun. 247:741-745.

Kim, H. I., Noh, T. H., Lee, C. S., and Park, Y. J. 2015. A mutation in the aroE gene affects pigment production, virulence, and chemotaxis in Xanthomonas oryzae pv. oryzae. Microbiol. Res. 170:124-130.

Klem, T. J., and Davisson, V. J. 1993. Imidazole glycerol phosphate synthase: The glutamine amidotransferase in histidine biosynthesis. Biochemistry 32 : 5177-5186.

Kulis-Horn, R. K., Persicke, M., and Kalinowski, J. 2014. Histidine biosynthesis, its regulation and biotechnological application in Corynebacterium glutamicum. Microbiol. Biotechnol. 7:5-25.

Lee, H. S., Cho, Y., Lee, J. H., and Kang, S. G. 2008. Novel monofunctional histidinol-phosphate phosphatase of the DDDD superfamily of phosphohydrolases. J. Bacteriol. 190:2629-2632.

Liang, X., Yu, X., Pan, X., Wu, J., Duan, Y., Wang, J., and Zhou, M. 2018. A thiadiazole reduces the virulence of Xanthomonas oryzae pv. oryzae by inhibiting the histidine utilization pathway and quorum sensing. Mol. Plant Pathol. 19:116-128

Niño-Liu, D. O., Ronald, P. C., and Bogdanove, A. J. 2006. Xanthomonas oryzae pathovars: Model pathogens of a model crop. Mol. Plant Pathol. 7:303-324.

Papaleo, M. C., Russo, E., Fondi, M., Emiliani, G., Frandi, A., Brilli, M., Pastorelli, R., and Fani, R. 2009. Structural, evolutionary and genetic analysis of the histidine biosynthetic "core" in the genus Burkholderia. Gene 448:16-28.

Park, Y. J., Song, E. S., Kim, Y. T., Noh, T. H., Kang, H. W., and Lee, B. M. 2007. Analysis of virulence and growth of a purine auxotrophic mutant of Xanthomonas oryzae pathovar oryzae. FEMS Microbiol. Lett. 276:55-59.

Polgár, L. 2005. The catalytic triad of serine peptidases. Cell. Mol. Life Sci. 62:2161-2172.

Poplawsky, A. R., and Chun, W. 1998. Xanthomonas campestris pv. campestris requires a functional pigB for epiphytic survival and host infection. Mol. Plant-Microbe Interact. 11:466-475.

Poplawsky, A. R., Urban, S. C., and Chun, W. 2000. Biological role of xanthomonadin pigments in Xanthomonas campestris pv. campestris. Appl. Environ. Microbiol. 66:5123-5127.
Qian, G., Liu, C., Wu, G., Yin, F., Zhao, Y., Zhou, Y., Zhang, Y., Song, Z., Fan, J., Hu, B., and Liu, F. 2013a. AsnB, regulated by diffusible signal factor and global regulator $\mathrm{Clp}$, is involved in aspartate metabolism, resistance to oxidative stress and virulence in Xanthomonas oryzae pv. oryzicola. Mol. Plant Pathol. 14:145-157.

Qian, G., Zhou, Y., Zhao, Y., Song, Z., Wang, S., Fan, J., Hu, B., Venturi, V., and Liu, F. 2013b. Proteomic analysis reveals novel extracellular virulenceassociated proteins and functions regulated by the diffusible signal factor (DSF) in Xanthomonas oryzae pv. oryzicola. J. Proteome Res. 12: 3327-3341.

Rajagopal, L., Sundari, C. S., Balasubramanian, D., and Sonti, R. V. 1997. The bacterial pigment xanthomonadin offers protection against photodamage. FEBS Lett. 415:125-128

Rebek, J. 1990. On the structure of histidine and its role in enzyme active sites. Struct. Chem. 1:129-131.

Schaad, N. W., and Stall, R. E. 1988. Xanthomonas. Pages 81-94 in: Laboratory Guide for Identification of Plant Pathogenic Bacteria, 2nd ed. N. W. Schaad, ed. American Phytopathological Society, St. Paul, MN.

Song, E. S., Park, Y. J., Noh, T. H., Kim, Y. T., Kim, J. G., Cho, H., and Lee, B. M. 2012. Functional analysis of the aroC gene encoding chorismate synthase from Xanthomonas oryzae pathovar oryzae. Microbiol. Res. 167: 326-331.

Starr, M. P. 1981. The genus Xanthomonas. Pages 742-763 in: The Prokaryotes. M. P. Starr, H. Stolp, H. G. Trüper, A. Balows, and H. G. Schlegel, eds. Vol. 1. Springer Verlag, Berlin.

Starr, M. P., and Stephens, W. L. 1964. Pigmentation and taxonomy of the genus Xanthomonas. J. Bacteriol. 87:293-302.

Stepansky, A., and Leustek, T. 2006. Histidine biosynthesis in plants. Amino Acids 30:127-142.

Wang, L., Makino, S., Subedee, A., and Bogdanove, A. J. 2007. Novel candidate virulence factors in rice pathogen Xanthomonas oryzae pv. oryzicola as revealed by mutational analysis. Appl. Environ. Microbiol. 73: 8023-8027.

Wiater, A., Krajewska-Grynkiewicz, K., and Klopotowski, T. 1971. Histidine biosynthesis and its regulation in higher plants. Acta Biochim. Pol. 18: 299-307.

Zhao, Y., Qian, G., Fan, J., Yin, F., Zhou, Y., Liu, C., Shen, Q., Hu, B., and Liu, F. 2012. Identification and characterization of a novel gene, $h s h B$, in Xanthomonas oryzae pv. oryzicola co-regulated by quorum sensing and clp. Phytopathology 102:252-259.

Zhao, Y., Qian, G., Yin, F., Fan, J., Zhai, Z., Liu, C., Hu, B., and Liu, F. 2011. Proteomic analysis of the regulatory function of DSF-dependent quorum sensing in Xanthomonas oryzae pv. oryzicola. Microbiol. Pathog. 50:48-55.

Zhou, L., Huang, T. W., Wang, J. Y., Sun, S., Chen, G., Poplawsky, A., and He, Y. W. 2013a. The rice bacterial pathogen Xanthomonas oryzae pv. oryzae produces 3-hydroxybenzoic acid and 4-hydroxybenzoic acid by XanB2 for use in xanthomonadin, ubiquinone, and exopolysaccharide biosynthesis. Mol. Plant-Microbe Interact. 26:1239-1248.

Zhou, L., Wang, J. Y., Wu, J., Wang, J., Poplawsky, A., Lin, S., Zhu, B., Chang, C., Zhou, T., Zhang, L. H., and He, Y. W. 2013b. The diffusible factor synthase XanB2 is a bifunctional chorismatase that links the shikimate pathway to ubiquinone and xanthomonadins biosynthetic pathways. Mol. Microbiol. 87:80-93.

Zou, L. F., Li, Y. R., and Chen, G. Y. 2011. A non-marker mutagenesis strategy to generate poly-hrp gene mutants in the rice pathogen Xanthomonas oryzae pv. oryzicola. Agric. Sci. China 10:1139-1150.

Zou, L. F., Wang, X. P., Xiang, Y., Zhang, B., Li, Y. R., Xiao, Y. L., Wang, J. S., Walmsley, A. R., and Chen, G. Y. 2006. Elucidation of the hrp clusters of Xanthomonas oryzae pv. oryzicola that control the hypersensitive response in nonhost tobacco and pathogenicity in susceptible host rice. Appl. Environ. Microbiol. 72:6212-6224. 